\title{
Centrality of an Urban Rail System
}

\author{
W. M. To ${ }^{1}$
}

Received: 24 November 2014/Revised: 14 December 2015 / Accepted: 4 January 2016/Published online: 22 January 2016

(C) The Author(s) 2016. This article is published with open access at Springerlink.com

\begin{abstract}
Railway re-emerges as one of the most important man-made physical systems in the world. Hundreds of million passengers travel by trains within cities. Hence, the management and maintenance of rail and station facilities are crucial. The paper introduces five centrality measures and explains whether and how these measures can be applied to the network analysis of urban rail systems. Centrality measures were used to identify the characteristics of Hong Kong's urban rail system. Results showed that betweenness centrality is the most appropriate measure to indicate the relative importance of a station based on its potential on strategic facility management and risk management in an urban rail system.
\end{abstract}

Keywords Urban rail system · Network analysis · Centrality

\section{Introduction}

Rail networks have been one of the prime movers of world economies since the industrial revolution [1]. People and goods have been transported by rail systems for centuries. In built environments, rail networks in the form of underground systems or elevated systems have become a symbol of modernization and commercialization [2] and play an important role in local public transport. Hundreds of millions

W. M. To

wmto@ipm.edu.mo

1 Macao Polytechnic Institute, Rua de Luis Gonzaga Gomes, Macao SAR, The People's Republic of China

Editor: Dr. Xuesong Zhou passengers commute in rolling stocks a day in cities and between cities [3, 4]. In fact, most rail networks were built because there were more than enough passengers to be carried by buses, coaches, and private cars on road surfaces. That forced governments to build mass transit rail networks from one location to another location, and so on to ease traffic jams and enhance the flow of people and commerce $[5,6]$. When a rail network is designed, town planners and traffic consultants identify the station locations based on the existing and projected populations and estimate traffic flow, i.e., how many passengers from location A to location B during the peak hours. From that, transport engineers choose a particular type of rolling stocks that meet the projected capacity [7]. However, urbanization will always lead to more people moving into the city and new residential and commercial areas will be developed, the rail development process will then be re-iterated and new rail networks need to be designed and linked to the existing network [8].

In recent years, China has spent several trillion yuan to construct inter-city high-speed rails and to expand metrosystems or undergrounds in major cities such as Shenzhen, Guangzhou, Shanghai, Beijing, etc. [3, 9] According to the official Xinhua News Agency [10], China invested 745.5 billion yuan (USD115 billion) in building railways in 2011 alone. As at the end of 2010, China had already taken the lead with more than $7000 \mathrm{~km}$ of high-speed railways in service in the world [9]. As the inter-city high-speed railway system that is a complex system involving engineering, social, and economic factors is affected by climatic and human factors, Ning et al. [9] developed parallel control and management system that incorporates artificial systems, computational experiments, and parallel execution (ACP) for rail planning and management. This ACP method and other complex network theories have also been applied to study system behaviors of urban rail 
transportation systems [11-13]. Nevertheless, the recent failures in some existing urban rail systems and their station facilities in Hong Kong, Shenzhen, Guangzhou, Shanghai, and Beijing have caused great concerns on how reliable urban rail systems are, particularly due to heavy loadings on station facilities. For example, Hong Kong's urban rail system (MTR system) carries over 70,000 passengers per hour per direction during peak hours.

To address such concerns, this paper describes an alternative approach that has five centrality measures (following the suggestions from Ning et al. $[9,11,12]$ who advocate the interaction between humans and engineering systems). Centrality measures have been developed in the social network analysis community since the 1950s. These measures can be applied to man-made networks, such as rail and road networks, and provide significant insights about the importance of rail stations and road intersections from different perspectives. In studying the city's network structure, researchers [14-16] transformed a city to a spatial network by treating street interactions as nodes and streets as edges. It was suggested that different centrality measures capture different aspects of city life [14-16]. Ramli et al. [17] demonstrated that one of the centrality measures, known as betweenness centrality, was statistically significantly correlated with passenger ridership data of Singapore's rapid transit system while $\mathrm{Tu}$ [18] reported that another centrality measure-closeness centrality was closely related to the operational condition of a rail line in an urban rail network. Nevertheless, the above articles were either published in physics journals [14, 15] or conference proceedings [16-18]. In fact, centrality has been mentioned sporadically in transportation-related journals in which centrality measures were used to locate the most accessible route in a network $[19,20]$, the shortest path of a network [21], and design the best shape for a crossdock [22].

The remainder of the paper is structured as follows. First, five centrality measures and their relationships with physical man-made network structures including rail systems are introduced in Sect. 2. Next, Hong Kong's MTR system, as one of the most advanced urban rail systems [23, 24], was used as a case study for illustrating the applicability of centrality measures to strategic facility management and risk management. Results were compared with some ridership data. Section 4 concludes the paper with implications and future research directions.

\section{Network Analysis, Centrality, and Its Applications}

A social network refers to a social structure that is made up of individuals, organizations, communities, or towns which are connected by one or more specific types of interdependency, such as friendship, financial exchange, social exchange, product exchange, and/or resource exchange.

Freeman [25] characterizes that social network analysis is indeed (i) a theory - a way of looking at the world or a social web, and (ii) a methodology — a set of techniques for making sense of a complex world, web, or structural network. Social network analysis considers relationships (called edges, links, or connections) between individuals or communities (called vertices or nodes) as directional/ bidirectional. The resulting graph-based structure is very simple when only a few individuals or communities are connected. However, the structure can be very complex when different kinds of ties interconnect a large number of individuals or communities [26].

To understand the role that each actor (individual, community, or location) plays in a structural network, a number of centrality measures have been proposed [2733]. Specifically, Freeman [34] reviewed the concepts of point and graph centrality and explained three measures of centrality, namely degree centrality, closeness centrality, and betweenness centrality, in great detail. He suggested that degree centrality can be viewed as the importance index of a node for its potential to participate in the communication activity. Betweenness centrality can be used as an index of the potential of a node for control of communication. On the other hand, closeness centrality can be viewed as a node's independence of such potential control by others [35]. Freeman's betweenness and closeness normally assume that whatever flows through the network moves only along the shortest possible paths, i.e., geodesic paths.

Bonacich [38] proposed eigenvector centrality that measures influence propagation in a network structure. Borgatti [36] explained that eigenvector centrality is similar to degree centrality, "the difference being that eigenvector centrality measures a long-term direct and indirect risk (or influence) while degree centrality measures immediate risk (influence) only" (p. 62). Freeman et al. [31] relaxed the shortest possible path criterion and proposed flow betweenness to measure the centrality effect due to all proper paths in which no node is visited more than once. Brin and Page [29] produced a variant of eigenvector centrality-PageRank and used it to identify the relative importance of a webpage in the World Wide Web, now known as Google's search.

\subsection{Centrality Measures}

Following Freeman's [34] terminology, we begin by presenting the mathematical formulation of the simplest measure of centrality-degree centrality. According to Freeman [34], degree centrality is the count of edges connected to a given node, $p_{k}$ : 
$C_{\mathrm{D}}\left(p_{k}\right)=\sum_{i=1}^{n} a\left(p_{i}, p_{k}\right)$,

where $a\left(p_{i}, p_{k}\right)=1$ if and only if $p_{i}$ and $p_{k}$ are connected by a line; 0 otherwise; and $\mathrm{n}$ is the total number of nodes. Degree centrality can also be calculated as the row sum (or column sum) of the adjacency matrix $\boldsymbol{A}$ as follows:

$C_{\mathrm{D}}\left(p_{k}\right)=\sum_{i=1}^{n} a_{i k}$,

where $a_{i k}$ is the $(i, k)$ element of matrix $\boldsymbol{A} . C_{\mathrm{D}}\left(p_{k}\right)$ is large if node $p_{k}$ is adjacent to (i.e., in direct contact with) a large number of nodes, and small if $p_{k}$ tends to be cut off from such direct contact. The magnitude of $C_{\mathrm{D}}\left(p_{k}\right)$ is normally dependent on the size of the network. Freeman [34] showed that for a given network, the maximum number of a node can at most be adjacent to $n-1$ other nodes, such as a star or wheel configuration. Therefore, the relative degree centrality can be written as

$C_{\mathrm{D}}^{\prime}\left(p_{k}\right)=\frac{\sum_{i=1}^{n} a\left(p_{i}, p_{k}\right)}{n-1}$.

The second centrality measure is closeness centrality. Sabidussi [33] suggested that the centrality of a node is measured by summing the geodesic distances from that node to all other nodes in the network. In fact, this is a measure of node decentrality or inverse centrality since it grows as points are far apart. If one lets $d\left(p_{i}, p_{k}\right)$ equal to the number of edges in the geodesic linking $p_{i}$ and $p_{k}$, then closeness centrality $C_{\mathrm{C}}\left(p_{k}\right)$ that is the inverse of Sabidussi's measure of the decentrality is written as

$C_{\mathrm{C}}\left(p_{k}\right)=\frac{1}{\sum_{i=1}^{n} d\left(p_{i}, p_{k}\right)}$.

As the case for degree centrality, closeness centrality is dependent on the size of the network. Hence, one cannot compare values of closeness centrality from networks of different sizes. Freeman [34] showed that the relative closeness centrality of a node $p_{k}$ be defined as

$C_{\mathrm{C}}^{\prime}\left(p_{k}\right)=\frac{n-1}{\sum_{i=1}^{n} d\left(p_{i}, p_{k}\right)}$.

$C_{C}^{\prime}\left(p_{k}\right)$ can be viewed as the inverse of the average distance between $p_{k}$ and the other nodes normalized by the minimum sum of distances $(n-1)$. Thus, it is a direct measure of distance-based node centrality. It takes a value of unity when $p_{k}$ is maximally close to all other points such as the central node of a star or wheel configuration. It shrinks as the average distance between $p_{k}$ and other nodes grows.

The third centrality measure is Freeman's betweenness centrality. If one assumes two nodes $p_{i}$ and $p_{j}$ to be indifferent with respect to which of several alternative geodesics through them they are connected, the probability of using one of the geodesics is $\frac{1}{g_{i j}}$, where $g_{i j}$ is the number of geodesics linking $p_{i}$ and $p_{j}$. If $g_{i j}(k)$ is the number of geodesics linking $p_{i}$ and $p_{j}$ that contains $p_{k}$, the probability $b_{i j}(k)$ that $p_{k}$ falls on the geodesics linking $p_{i}$ and $p_{j}$ is given as

$b_{i j}(k)=\frac{g_{i j}(k)}{g_{i j}}$.

This value is the partial betweenness of $p_{k}$ for the pair of $p_{i}$ and $p_{j}$. To determine the betweenness centrality of the node $p_{k}$, one can sum its partial betweenness values for all unordered pairs of nodes where $i \neq j \neq k$ as follows:

$C_{\mathrm{B}}\left(p_{k}\right)=\sum_{i=1}^{n} \sum_{j=i+1}^{n} b_{i j}(k)=\sum_{i=1}^{n} \sum_{j=i+1}^{n} \frac{g_{i j}(k)}{g_{i j}}$.

Like $C_{\mathrm{D}}\left(p_{k}\right)$ and $C_{\mathrm{C}}\left(p_{k}\right)$, betweenness centrality $C_{\mathrm{B}}\left(p_{k}\right)$ is dependent on the size of the network. Freeman [34] showed that the maximum value of $C_{\mathrm{B}}\left(p_{k}\right)$ is achieved only by the central node in a star. The maximum value is $\frac{n^{2}-3 n+2}{2}$. Therefore, the relative betweenness centrality is written as

$C_{\mathrm{B}}^{\prime}\left(p_{k}\right)=\frac{2 C_{\mathrm{B}}\left(p_{k}\right)}{n^{2}-3 n+2}$.

Borgatti and Everett [37] noted that "when the network being studied consists of ties that are very costly to build, betweenness will indeed index an ability to extort benefits from flows through the network" (p. 474). Pitts [28] studied the medieval river trade network of Russia and concluded that the cities with high betweenness centrality had opportunities for amassing wealth and exerting control over other cities.

The fourth measure of centrality is eigenvector centrality [28]. Eigenvector centrality is obtained from the principal eigenvector (the one associated with the largest eigenvalue) of the adjacency matrix $\boldsymbol{A}$ of the network. The eigen-equation is written as

$v=\lambda^{-1} \mathbf{A} \mathbf{v}$

where $v$ is the eigenvector and $\lambda$ is the corresponding eigenvector i.e., eigenpair. A number of fast algorithms such as Rayleigh Quotient Iteration [39] can be used to determine the largest eigenpair.

The eigenvector centrality is determined by

$C_{\mathrm{E}}\left(p_{k}\right)=\sum_{i=1}^{n} a_{k i} v_{i}$.

From Eq. (10), one can interpret that a node that has a high eigenvector centrality score is one that is adjacent to nodes that themselves having high scores. Indeed, 
eigenvector centrality is closely related to the influence measures proposed by researchers [32, 41, 42]. The fifth centrality measure is PageRank [29]. PageRank is a probability distribution used to represent the likelihood that a node (i.e., webpage) can be picked up via links initiated by a particular person. Mathematically speaking, if a vector $\boldsymbol{r}$ contains the PageRank values of $n$ webpages, it can be determined by solving the following equation iteratively.

$r_{i+1}=r_{0}+d \mathrm{~A}^{\prime} r_{\mathrm{i}} \quad$ for $i=0,1, \ldots$, until convergence;

where $\boldsymbol{r}_{\mathbf{0}}$ is the initial guess of $\boldsymbol{r}$ in which each element is $(1-d) / n, d$ is the damping factor which is normally set to 0.85 [29], and the adjacency function $a^{\prime}\left(p_{i}, p_{j}\right)$ is 0 if $p_{i}$ does not link to $p_{j}$ and normalized such that for each $j$,

$\sum_{i=1}^{n} a^{\prime}\left(p_{i}, p_{j}\right)=1$.

Hence, the PageRank values are the entries of the dominant eigenvector of the modified adjacency matrix $\boldsymbol{A}^{\text {' }}$ in which the elements of each column sum up to 1 . PageRank is a variant of eigenvector centrality.

\subsection{Flow Processes and Centrality Measures}

Section 2.1 presents some of the most commonly used centrality measures. The development of each measure has a historical background with certain underlying assumptions on flow process. Freeman [34] and Borgatti [36] provided clarification on their development and uses. Specifically, Borgatti [36] typified the mechanisms of dyadic diffusion into two major forms; one replication (copy mechanism) and another transfer (move mechanism). $\mathrm{He}$ also identified that some mechanisms assume things moving along the shortest distances-geodesics while others do not, like paths, trails, and walks. From that, Borgatti [36] provided a summary about which measures should be used for different flow processes. The summary is shown in Table 1.

In a rail network, people move around from one station to another station. This phenomenon is best characterized as a transfer process. Therefore, either betweenness centrality or closeness centrality is an appropriate measure depending on the objective of the study as suggested by Table 1. In fact, betweenness centrality can be considered as an index that represents the frequency of traffic one can observe flowing through a node across multiple instances. On the other hand, closeness centrality is an index that represents the length of time it takes traffic to reach a node (assuming train using the more or less same duration to travel from one station to another). For a rail operator,
Table 1 Flow processes and major centrality measures

\begin{tabular}{llll}
\hline & Duplication & \multirow{2}{*}{ Transfer } \\
\cline { 2 - 3 } & Parallel duplication & Serial duplication & \\
\hline Geodesics & Closeness & Closeness & Betweenness \\
Paths & Degree & & Closeness \\
& Closeness & \\
Trails & Degree & \\
& Closeness & \\
Walks & Degree & \\
& Eigenvector & \\
& PageRank & \\
\hline
\end{tabular}

*Adapted from Borgatti [36], p.63

betweenness centrality is a much more important indicator for facility management and risk management.

\section{An Example: Rail System(s) in Hong Kong}

In Hong Kong, the MTR Corporation operates a territorywide nine-line commuter rail system with a total length of $175 \mathrm{~km}$ and the $35 \mathrm{~km}$ Airport Express as shown in Fig. 1. The MTR Corporation started operating an urban line with 8 stations (now part of Kwun Tong Line) in 1979. In the 1990s, MTR's rail system expanded to three urban lines, namely Kwun Tong Line, Island Line, and Tsuen Wan Line, with 38 stations. In 2007, the MTR Corporation merged with another Hong Kong's rail operator (KCRC) that operated East Rail Line, Ma On Shan Line, and West Rail Line.

Figure 1 shows the commuter rail network operated by the MTR Corporation in 2014. By analyzing the rail network using the social network analysis software NodeXL, various centrality measures were obtained. Table 2 shows the rank order of rail stations based on betweenness, closeness, degree, eigenvector, and PageRank measures of centrality. It indicates that Kowloon Tong Station-an interchange between Kwun Tong Line and East Rail Line is the most important station based on betweenness, closeness, and degree centrality. Tai Wan Station-an interchange between East Rail Line and Ma On Shan Line is the second most important station based on betweenness centrality, followed by stations in Admiralty, Nam Cheung, Quarry Bay, Lai King, and Yau Tong_all are interchanges between two rail lines. On the other hand, Kowloon Tong Station is ranked 31 and 3 according to its eigenvector centrality and PageRank centrality, respectively. Comparing the rankings by betweenness centrality and closeness centrality, it was found that Quarry Bay Station and Yau 


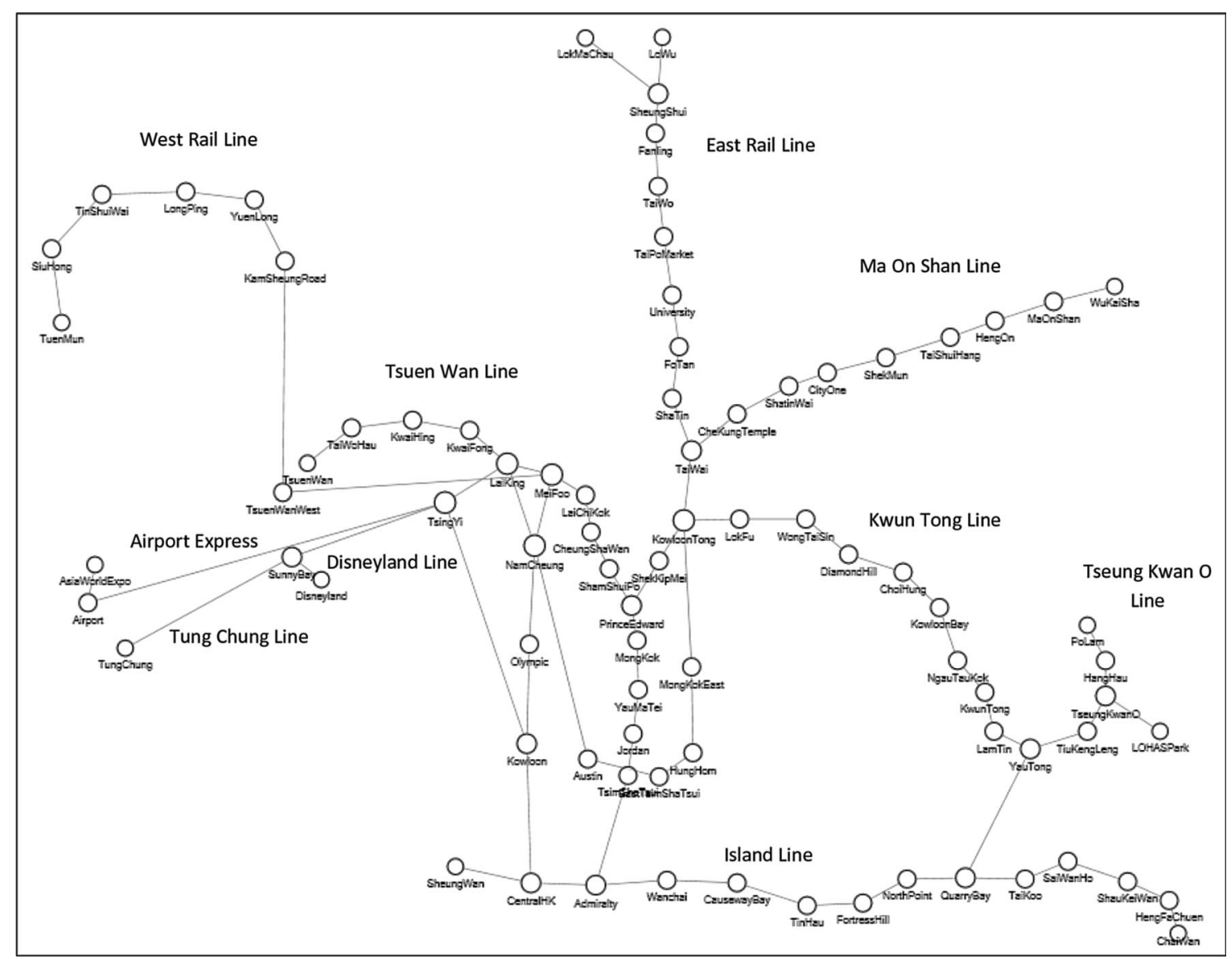

Fig. 1 Hong Kong's urban rail network in 2014

Table 2 Importance rank order of rail stations based on centrality measures

\begin{tabular}{llcccc}
\hline Rail Station & Betweenness & Closeness & Degree & Eigenvector & PageRank \\
\hline Kowloon Tong & 1 & 1 & 1 & 31 & 3 \\
Tai Wai & 2 & 11 & 6 & 39 & 14 \\
Admiralty & 3 & 15 & 6 & 20 & 12 \\
Nam Cheung & 4 & 2 & 1 & 2 & 7 \\
Quarry Bay & 5 & 48 & 6 & 56 & 10 \\
Lai King & 6 & 8 & 1 & 1 & 5 \\
Yau Tong & 7 & 50 & 6 & 59 & 9 \\
Wanchai & 8 & 26 & 16 & 28 & 54 \\
Lok Fu & 9 & 6 & 16 & 40 & 61 \\
\hline
\end{tabular}

Tong Station (two interchanges between two rail lines) have much lower rankings using closeness centrality. It is because both stations are the critical links serving both the eastern parts on both sides of Victoria Harbor but have relatively few stations on further east. Nevertheless, they are very important in completing the rail loop in most densely populated areas in Hong Kong.

Figure 2 shows the importance of rail stations weighted by betweenness centrality. The size of circle represents the relative value of betweenness centrality. Figure 2 indicated that as expected, interchange stations have higher rankings based on betweenness centrality, followed by their immediate next stations, etc. Figure 3 shows the importance of rail stations based on the MTR's network in 1990. It illustrated that the most important station based on betweenness centrality in 1990 was Prince Edward Station, followed by stations in Sham Shui Po, Quarry Bay, and Admiralty.

A comparison of Figs. 2 and 3 illustrates that the values of betweenness centrality changed when an urban rail network expanded. For example, Prince Edward Station 
254

Urban Rail Transit (2015) 1(4):249-256

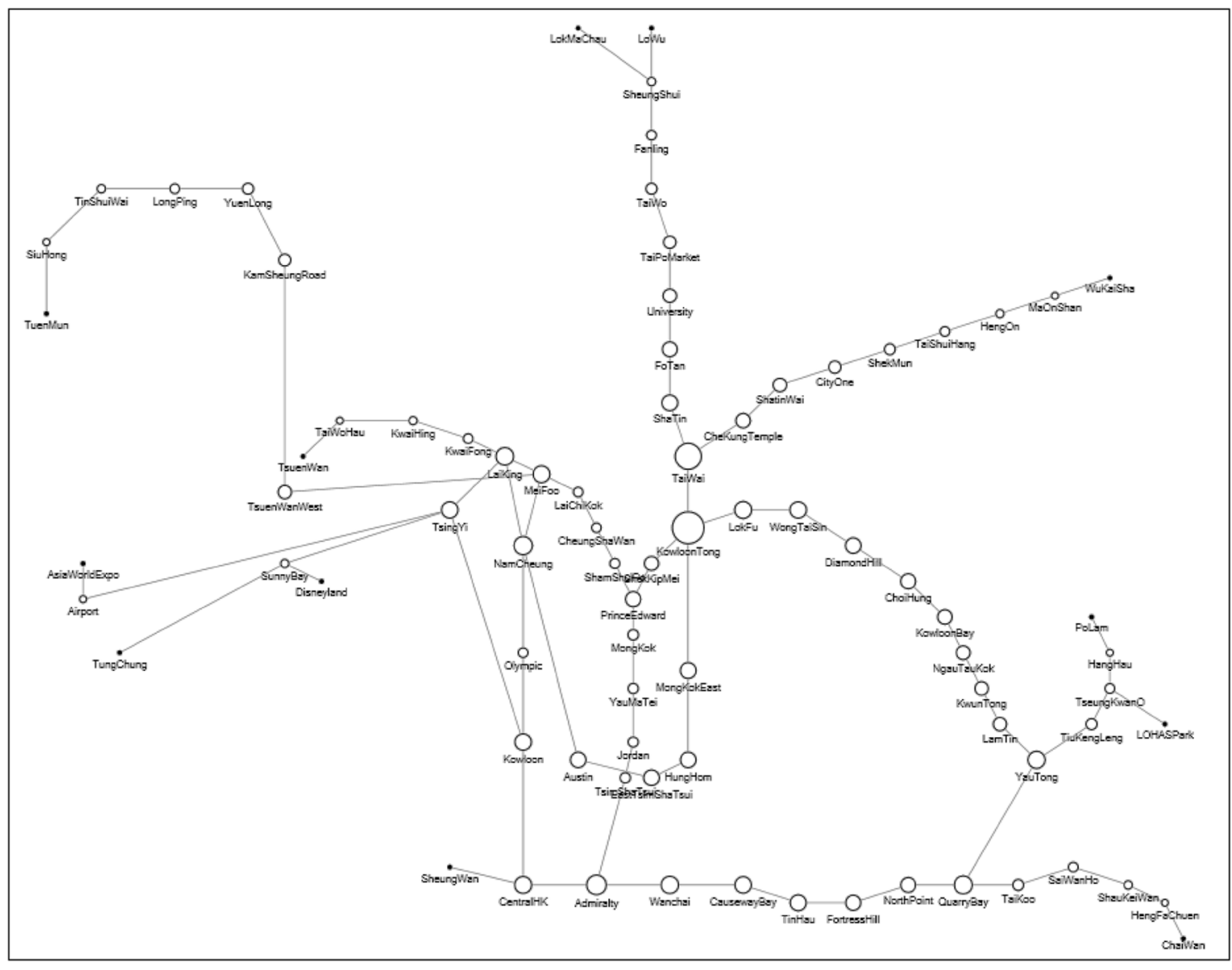

Fig. 2 The importance of rail stations weighted by betweenness centrality. Note The size of circle represents the relative value of betweenness centrality

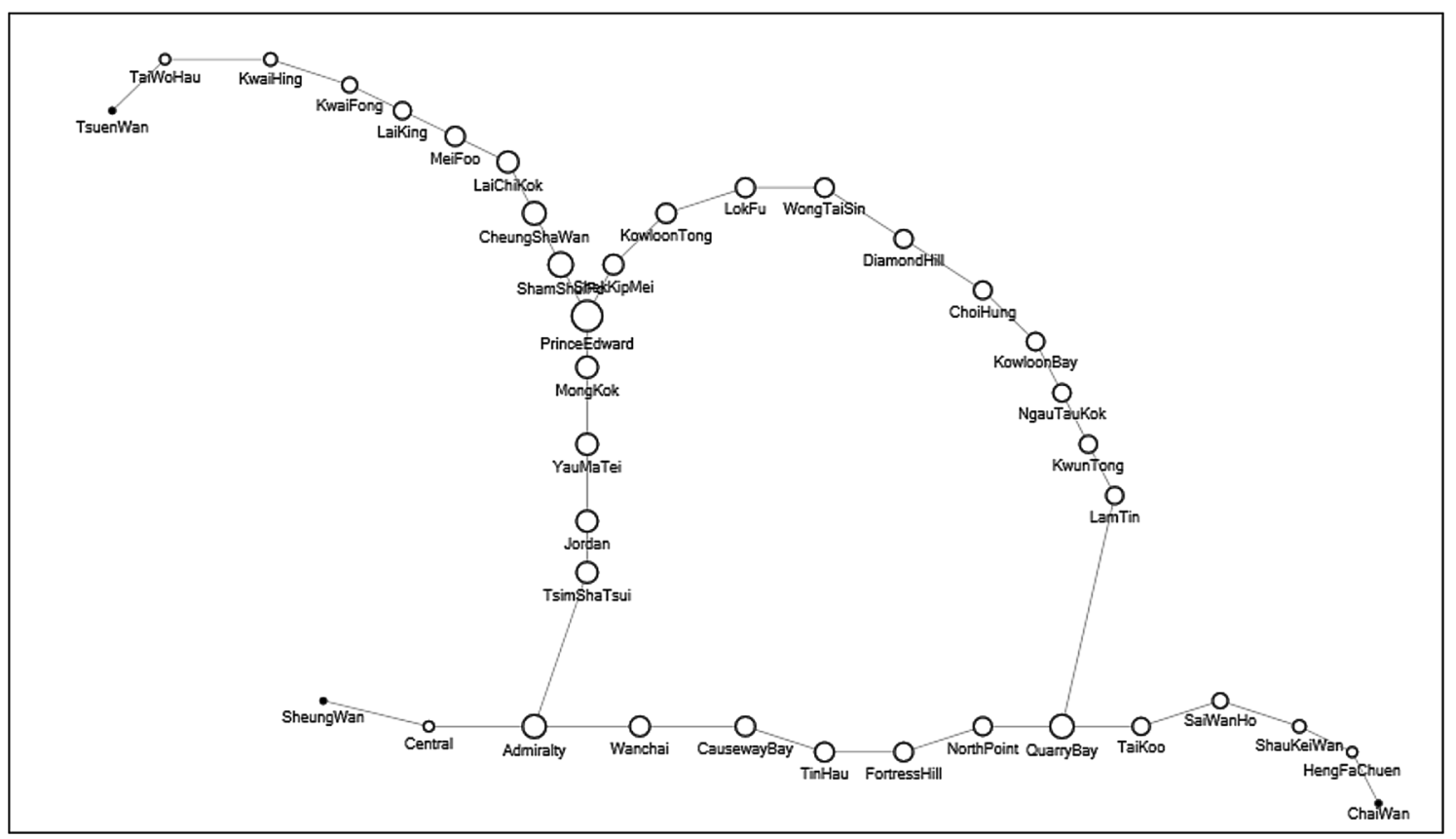

Fig. 3 The importance of rail stations weighted by betweenness centrality (MTR system in 1990). Note The size of circle represents the relative value of betweenness centrality

Springer 
was the most important station in 1990 and its ranking of importance in terms of betweenness centrality dropped to 25 in 2014. Hence, the degree of importance of a station is dynamic and depends on the development of the rail system.

Measurement data were obtained from MTR for the year of 2005 [42] before MTR Corporation merged with KCRC. Using the number of passengers boarding and alighting along four major line at that time (Island Line, Tsuen Wan Line, Kowloon Tong Line, and Tung Chun Line), it was found that five stations had the number of passengers boarding and alighting more than 10,000 during the peak 15-min period in the morning between 7:30 and 9:30 in weekdays. They were Admiralty of 22,100 passengers, Prince Edwards of 20,300 passengers, MongKok of 18,900 passengers, Central/Hong Kong of 15,800 passengers, and Quarry Bay of 12,500 passengers. All were interchanges of MTR Lines at that time.

\section{Conclusion}

Railway is one of the most important transportation modes because it is very efficient and environmentally friendly to carry a large number of passengers from one location to another [11, 43], in order to provide a quick and efficient evaluation of the relative importance of stations in an urban rail system for facility management and risk management. This paper introduces five centrality measures and provides a detailed historical review of their development, formulations, and applications. As argued by Freeman [30], betweenness centrality is one of the most important indicators for a vertex or node because it refers to the extent of the vertex that is structurally central for standing in between others and the vertex can therefore facilitate or impede the transmission of information/goods. Freeman [30] also cited the definition of betweenness centrality expressed by Shimbel [44] in 1953:

"Suppose that in order for site i to contact site $j$, site $k$ must be used as an intermediate station. Site $k$ in such a network has a certain 'responsibility' to sites $i$ and $j$. If we count all of the minimum paths which pass through site $k$, then we have a measure of the 'stress' which site $k$ must undergo during the activity of the network. A vector giving this number for each number of the network would give us a good idea of stress conditions throughout the system."

This paper shows that by applying betweenness centrality to the rail network in Hong Kong, a number of rail stations, especially those located at the interchanges between two rail lines, stand out to be the more important rail stations as expected. Nevertheless, the values of betweenness centrality show that not all of them have the same importance. For example, in Hong Kong's MTR system, Kowloon Tong Station is the most important rail station, followed by Tai Wai Station and Admiralty Station, then stations in Nam Cheung, Quarry Bay, Lai King, and Yau Tong having almost the same value of betweenness centrality. Besides, the relative importance of a station is dynamic and depends on the expansion of the rail system.

In practice, the most 'central' station is under the greatest stress because it carries the largest number of passengers either as an entrance and exit to the network or as a location for passengers changing commuter lines. Its ticketing machines, gates, escalators, lifts, information systems, screening doors, etc, serve the largest number of passengers. In sum, betweeness centrality truly reflects the importance of a rail station in terms of its usability and criticality.

Most advanced cities are dependent on reliable and safe rail networks to carry a large number of commuters from their homes to offices and then back homes [3, 9, 11, 12]. Moreover, tourists today are also relying on rail networks to travel from one scenic spot to another scenic spot in many cities. Hence, it is critically important for a rail operator to maintain a very high level of reliable services to their customers. Therefore, betweenness centrality can serve as a very useful tool for rail operators to plan their maintenance schedule because the more 'central' stations experience much more stress, resulting in high loadings on its facilities. In addition, rail operators and government officials shall also use this tool to access the risk associated when a particular station is interrupted accidentally or on purpose. It should be noted that centrality measures can be applied to inter-city rail systems such as high-speed rail networks. However, when a high-speed rail network is linked to an urban rail network, great caution should be exercised because high-speed rail and urban rail are very different in terms of capacity and frequency. Future research should explore the interconnectedness of different rail networks.

Acknowledgments The author gratefully acknowledges the constructive comments and suggestions from two anonymous reviewers.

Open Access This article is distributed under the terms of the Creative Commons Attribution 4.0 International License (http://creati vecommons.org/licenses/by/4.0/), which permits unrestricted use, distribution, and reproduction in any medium, provided you give appropriate credit to the original author(s) and the source, provide a link to the Creative Commons license, and indicate if changes were made.

\section{References}

1. Szostak R (1991) The role of transportation in the industrial revolution: a comparison of England and France. McGill-Queen's University Press, Montreal 
2. Ito K, Chiba M (2001) Railway stations and local communities in Japan. Japan Railw Transp Rev 28:4-17

3. Ning B, Tang T, Gao Z, Yan F, Wang FY, Zeng D (2006) Intelligent railway systems in China. IEEE Intell Syst 21(5):80-83

4. Martin JC (2011) Transportation changes in Europe. Transp J 50(1):109-124

5. Gendreau M, Laporte G, Mesa JA (1995) Locating rapid transit lines. J Adv Transp 29(2):145-162

6. Sugawara M (1995) Urban transportation in Asian countries. Japan Railway and Transport Review 4:23-29

7. Griffin KW (2004) Building type basics for transit facilities. Wiley, New York

8. Li ZC, Lam WH, Wong SC (2011) On the allocation of new lines in a competitive transit network with uncertain demand and scale economies. J Adv Transp 45(4):233-251

9. Ning B, Tang T, Dong H, Wen D, Liu D, Gao S, Wang J (2011) An introduction to parallel control and management for high-speed railway systems. IEEE Trans Intell Transp Syst 12(4):1473-1483

10. Xinhua News (2011) China's railway investment to top 700 billion yuan this year. Xinhua News Agency; Available at: http:// news.xinhuanet.com/english2010/china/2011-05/06/c_13862459. htm

11. Ning B, Wang FY, Dong HR, Li RM, Wen D, Li L (2010) Parallel systems for urban rail transportation based on ACP approach. J Transp Syst Eng Inf Technol 10(6):22-28

12. Ning B, Dong HR, Wen D, Li L, Cheng CJ (2011) ACP-based control and management of urban rail transportation systems. IEEE Trans Intell Transp Syst 26(2):84-88

13. Ma JQ, Bai Y, Han BM (2010) Characteristic analysis of basic unit and complex network for urban rail transit. J Traffic Transp Eng 10(4):66-70

14. Crucitti P, Latora V, Porta S (2006) Centrality in networks of urban streets. Chaos: an Interdisciplinary. J Nonlinear Sci 16(1):015113

15. Crucitti P, Latora V, Porta S (2006) Centrality measures in spatial networks of urban streets. Phys Rev E 73(3):036125

16. Scheurer J, Curtis C, Porta S (2007) Spatial network analysis of public transport systems: developing a strategic planning tool to assess the congruence of movement and urban structure in Australian cities. Proceedings of the 30th Australasian Transport Research Forum (ATRF), Melbourne, September 2007

17. Ramli MA, Monterola CP, Khoon GLK, Guang THG (2014) A method to ascertain rapid transit systems' throughput distribution using network analysis. Procedia Computer Science 29:1621-1630 (Proceedings of the 2014 International Conference on Computational Science)

18. Tu Y (2013) Centrality characteristics analysis of urban rail network. Proceedings of the 2013 IEEE International Conference on Intelligent Rail Transportation

19. Smith PN (1993) Fuzzy evaluation of potential suburban railway station locations. J Adv Transp 27:153-179

20. Slater PJ (1982) Locating central paths in a graph. Transp Sci $16(1): 1-18$
21. Hedetniemi SM, Cockayne EJ, Hedetniemi ST (1981) Linear algorithms for finding the Jordan center and path center of a tree. Transp Sci 15(2):98-114

22. Bartholdi JJ, Gue KR (2004) The best shape for a crossdock. Transp Sci 38(2):235-244

23. Lam WHK, Cheung CY, Poon YF (1998) A study of train dwelling time at the Hong Kong Mass Transit Railway System. J Adv Transp 32(3):285-296

24. Tian Z, Yang H, Lam WHK (1997) Transit assignment under crowded conditions. J Adv Transp 31(1):19-38

25. Freeman LC (2004) The development of social network analysis: a study in the sociology of science. Empirical Press, Vancouver

26. Borgatti SP, Mehra A, Brass DJ, Labianca G (2009) Network analysis in the social sciences. Science 323:892-895

27. Bavelas A (1950) Communication patterns in task oriented groups. J Acoust Soc Am 22(6):725-730

28. Bonacich P (1987) Power and centrality: a family of measures. Am J Sociol 92(5):1170-1182

29. Brin S, Page L (1998) The anatomy of a large-scale hypertextual web search engine. Comput Netw 30(1-7):107-117

30. Freeman LC (1977) A set of measures of centrality based on betweenness. Sociometry 40(1):35-41

31. Freeman LC, Borgatti SP, White DR (1991) Centrality in valued graphs: a measure of betweenness based on network flow. Soc Netw 13(2):141-154

32. Katz L (1953) A new index derived from sociometric data analysis. Psychometrika 18:39-43

33. Sabidussi G (1966) The centrality index of a graph. Psychometrika 31:581-603

34. Freeman LC (1979) Centrality in social networks: conceptual clarification. Soc Netw 1(3):215-239

35. Freeman LC (1980) The gatekeeper, pair-dependency and structural centrality. Qual Quant 14(4):585-592

36. Borgatti SP (2005) Centrality and network flow. Soc Netw 27(1):55-71

37. Borgatti SP, Everett MG (2005) A graph-theoretic perspective on centrality. Soc Netw 28(4):466-484

38. Pitts FR (1979) The medieval river trade network of Russia revisited. Soc Netw 1:285-292

39. To WM, Ewins DJ (1990) Structural modification analysis using Rayleigh Quotient Iteration. Int J Mech Sci 12(3):169-179

40. Friedkin NE (1991) Theoretical foundations for centrality measures. Am J Sociol 96(6):1478-1504

41. Hubbell CH (1965) An input-output approach to clique identification. Sociometry 28(4):377-399

42. Fung WC (2005) Calibration and Validation of Transit Network Assignment Models. MPhil Thesis, The University of Hong Kong

43. To WM (2015) Greenhouse gases emissions from the logistics sector: the case of Hong Kong, China. J Clean Prod 103:658-664

44. Shimbel A (1953) Structural parameters of communication networks. Bull Math Biophys 15:501-507 